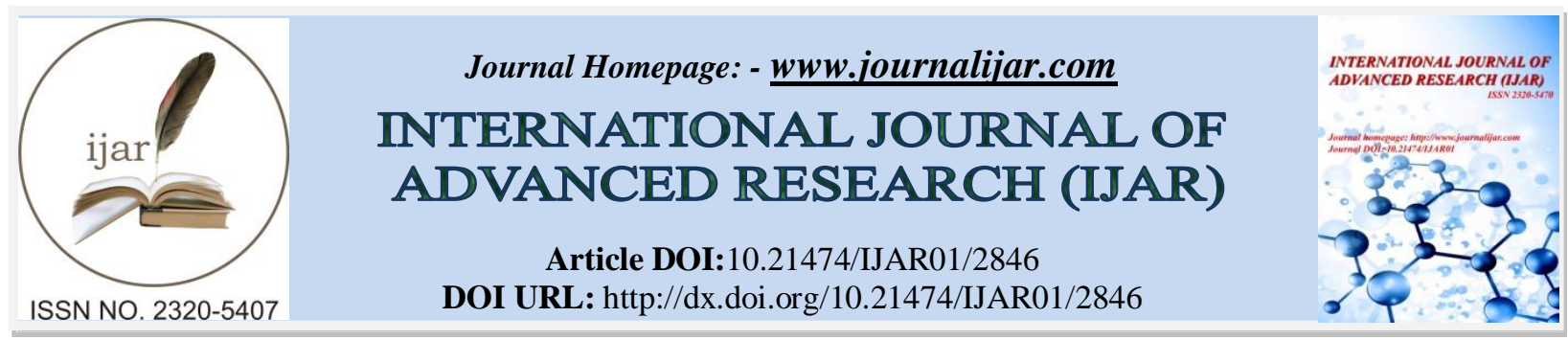

RESEARCH ARTICLE

\title{
RECYCLED POLYPROPYLENE/BOEHMITE ALUMINA NANOCOMPOSITES: ENHANCED STRUCTURE, THERMAL AND MECHANICAL PROPERTIES.
}

\section{Jayaramudu Jarugala ${ }^{1}$, Jeevan PreshdReddy. $D^{2}$, Rajkumar Kasilingam ${ }^{1}$, Manohar Nawale ${ }^{1}$, Suchismita Sahoo ${ }^{1}$, Siva Mohan Reddy Goddeti ${ }^{3}$, Babul Reddy Abbavaram ${ }^{4}$, Suprakas Sinha Ray ${ }^{3}$ and E. Rotimi Sadiku $^{4}$}

1. Indian Rubber Manufacturers Research Association,Wagle Industrial Estate,Thane (W), Mumbai- 400604, India

2. SreeVidyanikethan Engineering College, SreeSainath Nagar,Tirupati, A.Rangampet, AndhraPradesh-517102, India

3. Department of Applied Chemistry, University of Johannesburg, Doornfontein 2028,Johannesburg, South Africa

4. Department of Polymer Technology,Tshwane University of Technology, CSIR Campus, Building $14^{\mathrm{D}}$, Private Bag X025, Lynwood Ridge 0040,Pretoria, South Africa

\section{Manuscript Info}

Manuscript History

Received: 19 November 2016

Final Accepted: 21 December 2016

Published: January 2017

\section{Key words:-}

Recycled polypropylene, Boehmite alumina, Nanocomposites,Morphology, X-ray diffraction, Thermal properties, Mechanical Properties.

\section{Abstract}

Boehmite alumina (BAL) powder was investigated in terms of its use as a filler in PP in order to improve the inherent properties of recycled polypropylene. Nanocomposites of recycled polypropylene with different loadings of BLA were prepared by melt compounding technique. The structural characterization and morphology of BAL nanopowder were characterized by X-ray diffraction (XRD) and Transmission electron microscope (TEM). The influence of BAL nanoparticle content on the thermal properties of recycled polypropylene (PP) was studied by means of differential scanning calorimetry (DSC) and thermogravimetric analysis (TGA). The effect of the BAL content on the mechanical properties and morphological analyses (SEM) of recycled PP/BAL nanocomposites was also studied. It was found that BAL significantly affected the crystallization temperature and the degree of crystallization of recycled PP. The results showed that the BAL effectively improved the mechanical properties of recycled PP. In comparison with neat PP, the tensile strength of PP/BAL (3 wt\%) nanocomposites increased by $\sim 21 \%$ and the modulus increased by $\sim 101 \%$. Recycled polypropylene/boehmite alumina nanocomposites have such properties that advise their relevance for application in the packaging industries.

Copy Right, IJAR, 2016,. All rights reserved.

\section{Introduction:-}

With the increasing usage of polymers, dwindling petroleum resources and high oil prices, there is the search for alternative virgin polymers. This search will also consider the financial viability of materials rather than produce them from raw materials. Recycling is a viable alternative to reduce the disposal of plastic products which contributes significantly to the negative environmental impact. Among all polymers, polypropylene (PP) is one of the most common plastic materials that is being used in various applications [1]. Therefore, annually,millions of tons 
of PP materials are discarded as wastes and they are required to be recycledin orderto reduce plastic waste. However, during the recycling process, polypropylene undergoes various operations that bring out several modifications in the molecular structure. As a result, the mechanical, thermal and melt flow properties of the recycled products and their structural organization are quite different when compared to those composed of virgin material [2]. Several approaches have been made to improve the processability, mechanical and thermal properties of therecycled PP. These include: blending with the other polymers, addition of reinforcing agents, such as: nanofillers, natural fibers and other reinforcing fillers.

Recycled PP has been blended with virgin PP in order to improve its mechanical and thermal properties. Raj et al. reported that a 10\% virgin PP was the best combination to improve the mechanical properties of the recycled PP [2]. Sawdust has been used to improve the impact strength of the recycled PP [3]. Recycled PP were also utilized to produce co-composites with kenaf fiber [4]. In addition, secondary fiber (from the paper industry) reinforced recycled polypropylene composites have been successfully processed by extrusion by using $2 \%$ maleic anhydride modified polypropylene that acts as an efficient compatibilizer and promotes interfacial adhesion between secondary fiber and recycled polypropylene [5]. Besides that, nano $\mathrm{CaCO}_{3}$ filler was also utilized to improve the mechanical and thermal properties of recycled PP [6]. However, for the first time,Boehmite aluminawas used as a filler to improve the mechanical and thermal properties of recycled PP. Boehmitealumina(BAL) with chemical composition $\mathrm{AlO}(\mathrm{OH})$ is an inexpensive nanofiller and it can also be produced synthetically,in particulates form, with different aspect ratios. Boehmite nanocomposites with recycled LDPE has already been reported in a previous study [7].

The main objective of this study is to use low cost boehmitenanofiller as a reinforcing agentin order to improve the properties ofthe recycled PP, using a melt compounding technique and to investigate the effect of the recycled PP and BAL loadings (ranging from 1 and $5 \mathrm{wt} \%$ ) in order to get a better dispersion of BAL in the recycled PP matrix. Moreover, the influence of BAL on the structure, thermal and mechanical properties oftherecycled PP was investigated in detail by using different techniques.

\section{Experimental:- \\ Materials:-}

The recycled polypropylene was obtained from R.K. Polymers, South Africa. The BAl powder containing $80 \%$ $\mathrm{Al}_{2} \mathrm{O}_{3}$ used is a commercial product manufactured by SASOL, under the trade name Disperal 40. With several years of experience, SASOL developed this product that is not only high in dispersibility, but also with significantly lowlevels of common impurities, such as: iron, sodium and silica.

\section{Processing of recycled PP/ Boehmite aluminananocomposites:-}

PP/BAL nanocomposites were preparedby using an extruder, equipped with co-rotating twin-screws. The processing temperature was $165^{\circ} \mathrm{C}$ and the screw rotation speed of the microextruder was fixed at $100 \mathrm{rpm}$. After the fixed processing time $(2 \mathrm{~min})$ in the micro-extruder, the molten mixture was transferred to a pre-heated micro-injection moulding machine. The injection mould temperature was maintained at $40^{\circ} \mathrm{C}$. Finally, the specimen was conditioned according to ASTM standards, prior to testing. In order to investigate the performance of the nanocomposites, the loading of the BAL in the recycled PP matrix was varied from 1 to $5 \mathrm{wt} . \%$.

\section{Mechanical Properties:-}

Tensile testing of the composite specimens was carried out by using a UTM (Universal Testing Machine), Instron 3382 instrument, as per the ASTM D638. For this, rectangular specimens $(2.54 \times 15 \mathrm{~cm})$ from each sample were stretched at a cross-head speed of $50 \mathrm{~mm} / \mathrm{min}$. Ten replicates were tested for each sample and the average values are presented.

\section{Morphology Analysis:-}

The microstructure of the surface of the tensile fractured composites was observed using a Field Emission Scanning Electron Microscopy (FE-SEM) (S-4800, Hitachi Co., Ltd., Matsuda, Japan), operated at an accelerating voltage, $\mathrm{V}_{\mathrm{acc}}$ of $10 \mathrm{kV}$ and a current, Ie of $10 \mu$ Awith samples coated in vacuum with sputter of Os. The morphology of BAL was observed using a Transmission electron microscope (TEM) (JEM-2100F, JEOL, Japan). 


\section{Differential Scanning Calorimetry (DSC):-}

The thermal properties of the samples were determined using a DSC 22 System, Seiko Instruments, Inc., Japan. The heating rate used was $10^{\circ} \mathrm{C} / \mathrm{min}$, in a temperature range of between $30-300^{\circ} \mathrm{C}$ under nitrogen atmosphere. The percentage crystallinity was determined using the following equation (1).

$\mathrm{X}_{\mathrm{c}}(\%$ Crystallinity $)=\left[\left(\Delta \mathrm{H}_{\mathrm{m}}-\Delta \mathrm{H}_{\mathrm{c}}\right) / \Delta \mathrm{H}_{\mathrm{mo}}\right] \cdot 100 \%$

where $\Delta \mathrm{H}_{\mathrm{m}}$ is the enthalpy heat of fusion and $\Delta \mathrm{H}_{\mathrm{c}}$ is the heat of cold crystallization (in $\mathrm{J} / \mathrm{g}$ ). The term $\Delta \mathrm{H}_{\mathrm{mo}}$ is a reference value and represents the enthalpy heat of melting of an "ideally" $100 \%$ crystalline polymer.

\section{Thermo-gravimetric analysis (TGA):-}

The thermal stability of the recycled PP and recycled PP/nanocomposite samples was determined with athermogravimetric analyzer (TGA, Mettler Toledo, Schwarzenbach, Switzerland). About $5 \mathrm{mg}$ of each sample was heated from room temperature to $600^{\circ} \mathrm{C}$ at a heating rate of $10^{\circ} \mathrm{C} / \mathrm{min}$ under a nitrogen flow rate of $50 \mathrm{~cm}^{3} / \mathrm{min}$.

\section{X-ray diffraction (XRD):-}

X-ray diffraction (XRD) pattern of the BAL was analyzed by using a PANalyticalXpert pro MRD diffractometer (Amsterdam, Netherlands). The XRD spectra were recorded using $\mathrm{aCu}-\mathrm{K}_{\alpha}$ radiation (wavelength of $0.1546 \mathrm{~nm}$ ) with a nickel monochromator filtering wave at a voltage and current of $40 \mathrm{kV}$ and $30 \mathrm{~mA}$, respectively. The diffraction patterns were obtained at diffraction angles between $5^{\circ}$ and $70^{\circ}$ at a scanning rate of $0.4^{\circ} / \mathrm{min}$ at room temperature.

\section{Results and Discussion:-}

\section{TEM and X-ray diffraction analysis of BAL:-}

The morphology of BAL nanopowder are shown in Fig. 1 (a). TEM images of the BAL exhibited some hexagonal, flake and rod-like shapes. It can also be observed that the BAL is slightly aggregated, with some particles clustered to each other. This slight aggregation of nanoparticles may be due to the drying process during the sample preparation. These self-aggregated nanoparticles are expected to be separated during the melt-mixing with the recycled PP. The crystalline structure of BAL nanopowder was observed by doing the XRD analysis. Fig. 1(b) shows the XRD pattern of BAL nanopowder. From the X-ray diffractogram of BAL nanopowder, intense peaks ( $h k l$ plane) at $2 \theta=14.7^{\circ}, 28.5^{\circ}, 38.6^{\circ}, 49.5^{\circ}$ and $55.5^{\circ}$ were recorded, which indicate the presence of typical orthorhombic crystalline form of BA [7-8].

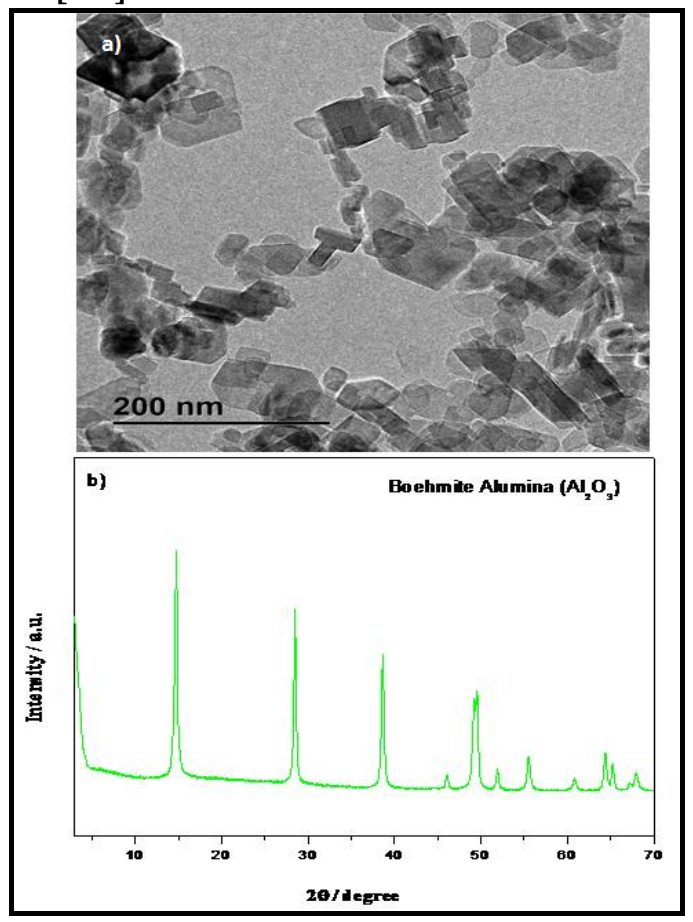

Fig. 1:- (a) TEM micrograph and (b) XRD patterns of BAL nanopowder. 


\section{Tensile properties:-}

The effect of BAL nanofiller content on the tensile properties of the recycled PP matrix is presented in Table 1. The mechanical properties of the recycled PP/BAL nanocomposites are significantly changed after blending with the BAL and the properties are influenced by the amount of the BAL nanopowder inclusion. The tensile strength increased from 18.4 $\pm 2.3 \mathrm{MPa}$ of the neat recycled PP to $22.3 \pm 1.2 \mathrm{MPa}$ with $3 \mathrm{wt} \%$ addition and then decreased with further addition of the BAL nanofiller. However, the strength of the recycled PP nanocomposites (with the highest amount of the BAL) is still higher than that of the neat recycled PP. The increased tensile strength of PP/BAL nanocomposites may be due to the better dispersion of BAl in to the PP matrix.

However, such reinforcing effect of the BAL nanopowder was reduced at high level of BAL additions ( 3 to 5 wt $\%$ ). This is probably due to the formation of aggregation of the BAL at higher loading. Above $3 \mathrm{wt} \%$ of BAL loading, the interaction between the BAL nanopowder and polymer matrix is due to the non-uniform stress distribution in the composite, which consequently reduced the strength of the recycled PP nanocomposite. The tensile test result suggests that there is an optimum concentration of the BAL nanopowder in order to induce maximum increment of the strength of the recycled PP nanocomposite.

Table 1:- Tensile properties of PP and PP/BAL nanocomposites

\begin{tabular}{|l|l|l|l|}
\hline Composites & TS (MPa) & TM (MPa) & EB (\%) \\
\hline PP & $18.4 \pm 2.3$ & $91.8 \pm 40.6$ & $522 \pm 121$ \\
\hline PP/BAL1\% & $21.3 \pm 1.6$ & $157 \pm 10$ & $775 \pm 95.2$ \\
\hline PP/BAL2\% & $21.1 \pm 1.5$ & $161 \pm 18.6$ & $748 \pm 72.2$ \\
\hline PP/BAL3\% & $22.3 \pm 1.2$ & $184 \pm 16.8$ & $657 \pm 81.8$ \\
\hline PP/BAL 4\% & $21.7 \pm 1.6$ & $184.3 \pm 27$ & $681 \pm 112$ \\
\hline PP/BAL5\% & $20.5 \pm 0.9$ & $166 \pm 13$ & $719 \pm 59.5$ \\
\hline
\end{tabular}

The tensile modulus (TM) of the recycled PP nanocomposites, which measures the extent or degree of stiffness of a plastic, also increased linearly with increasing concentration of BAL, up to $4 \mathrm{wt} \%$. The stiffness of the recycled PP/BAL nanocomposites increased by $101 \%$ more than the neat recycled PP, when 3 and $4 \mathrm{wt} \%$ of the BAL were included. Streller et al. reported that the moduli of boehmite aluminareinforced recycled PP nanocomposites are due to the increased stiffness [9]. The elongation-at-break (EB), which measures the flexibility or ductility, of a material also varied, depending on the content of BAL. The pattern of change in the EB of recycled PP/BAL nanocomposites was similar to that of the tensile strength (TS), namely, it increased with increase in the content of BAL up to 5 wt $\%$. The main advantage of the addition of BAL in the recycled PP is that there is no reduction in the EB, even at 5 weight \% loading, which was reported by Svoboda et al. for similar nanocomposites [10]. Usually, the decrease in the flexibility of the composite, observed at high concentration of the filler is due to the restricted mobility of polymer strand, caused by the increased stiffness of the recycled PP nanocomposites.

\section{SEM analysis:-}

The tensile fractured surface of the neat recycled PP (i.e. without addition of nanofiller) and the recycled PP/BAL nanocomposites are presented in Fig.2. The fractured surface ofthe recycled PP shows brittle failure in layered planes. The presence of some cracks and slip lines are also observed. With the addition of BAL nanopowder, the fractured surface of the recycled PP nanocomposites fractured surface topography,changed (Fig.2. (b), (c)). Fig.2 (b) and 2(c) are the representative SEM micrographs of the tensile fractured surfaces of the recycled PP/BAL nanocomposite samples with 1 and $2 \mathrm{wt} . \%$ of nanofiller, respectively.

From Fig.2 (b), (c) the presence of rough surfaces and the occurrence of many short, rounded tear linesare highly discernableand the extent of which increases with $2 \mathrm{wt} \%$ BAL concentration. The filler particles, due to thebetter polymer-filler interaction and adhesion, act as stress risers and hinder the smooth propagation of the stress paths. As a result, the elastic stored energy and tensile strength were found to be concomitantly improved with nanofiller addition [11]. 


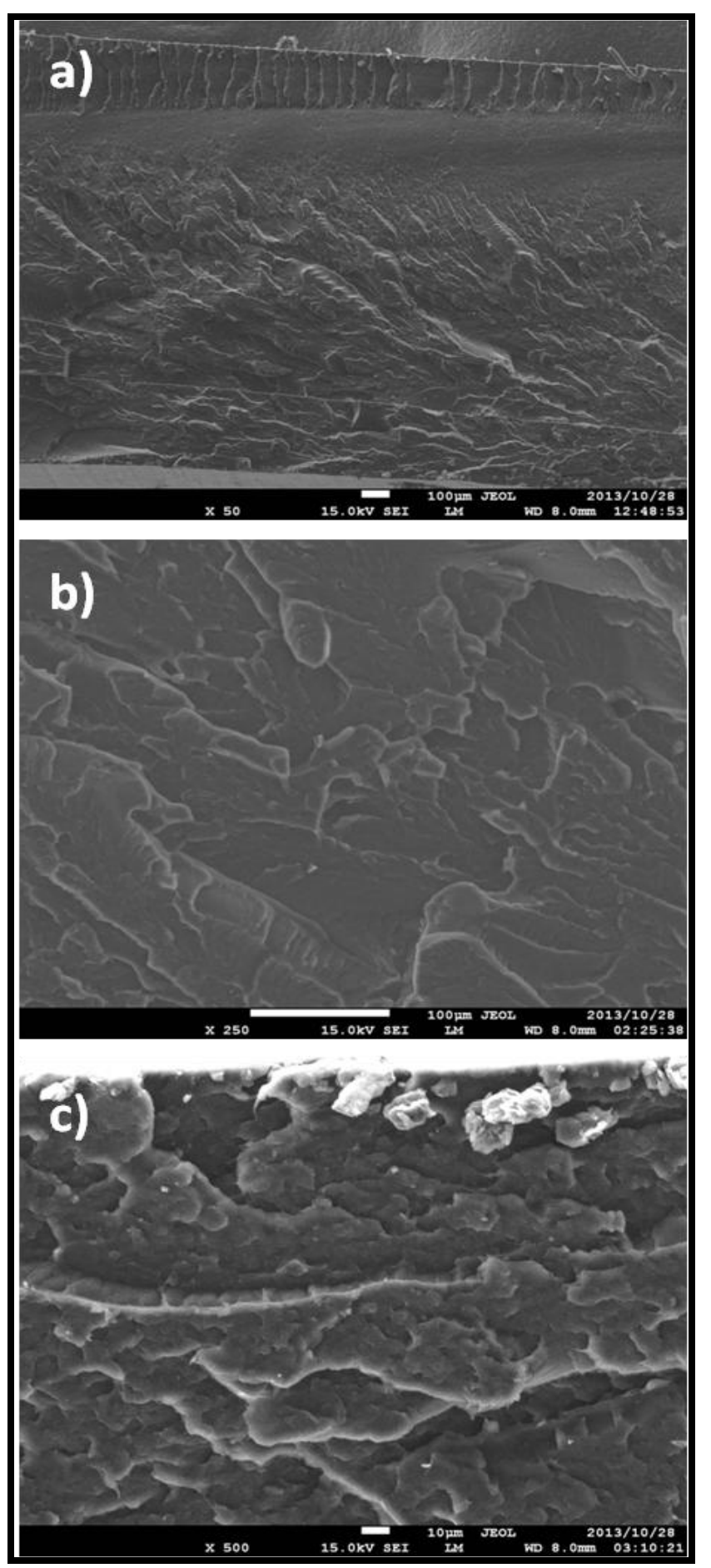

Fig. 2:-SEM micrographs of tensile fractured (a) PP, (b) PP/1\% BAL and (c) PP/2\% BAL

DSC Analysis:-

The degree of crystallinity and the change in crystallization temperature of PP and its nanocomposites were analyzed using the DSC. The results of the melting temperature and the percentage crystallinity are presented in Table2. 


\begin{tabular}{|c|c|c|c|c|}
\hline Composites & $\mathrm{T}_{\mathrm{m}}\left({ }^{\mathrm{o}} \mathrm{C}\right)$ & $\mathrm{T}_{\mathrm{c}}\left({ }^{\circ} \mathrm{C}\right)$ & $\Delta \mathrm{H}_{\mathrm{m}}(\mathrm{w} / \mathrm{g})$ & $\mathrm{X}_{\mathrm{c}}(\%)$ \\
\hline PP & 107 & 98 & 78.3 & 41.7 \\
\hline PP/BAL1\% & 108 & 98.2 & 79.6 & 45.0 \\
\hline PP/BAL2\% & 108 & 98.7 & 84.1 & 47.8 \\
\hline PP/BAL3\% & 109 & 99.3 & 83.7 & 45.3 \\
\hline PP/BAL4\% & 133 & 76.3 & 81.1 & 42.7 \\
\hline PP/BAL5\% & 132 & 76.2 & 82.5 & 43.6 \\
\hline
\end{tabular}

Table 2:-DSC analysis of PP and PP/BAL nanocomposites

The crystallization exotherms and endotherm peaks of PP and PP/BAL nanocomposites at various compositions are presented in Fig. 3(a) and 3(b). From these curves, it can be observed that the melting temperature of PP shifted to higher temperature with increasing BAL contents. High melting exothermic peak was observed in nanocomposites with 4 and 5 with $\%$ BAL contents.

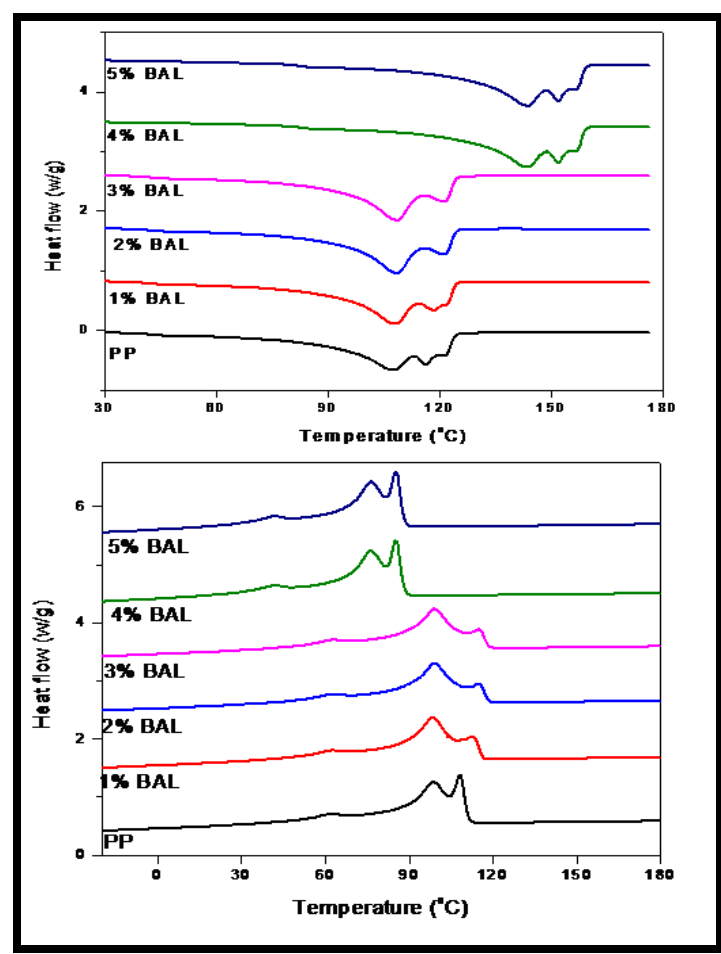

Fig. 3:-DSC analysis of PP/BAL nanocomposites

This increase in the melting temperature, clearly supports the crystallinity data. It is well known that highly crystalline samples possess better thermal stability [12]. In the cooling scan (Fig . $\mathbf{3}(\mathbf{b})$ ), the thermograms of neat recycled PP and recycled PP/BAL nanocomposites, show a peak of melt crystallization temperature $\left(\mathrm{T}_{\mathrm{c}}\right)$. The thermogram of the recycled PP/BAL nanocomposite shows similar trend as neat recycled PP, but the $\mathrm{T}_{\mathrm{cs}}$ of thecomposites are higher than that of neat recycled PP. The degree of crystallinity of recycled PP/BAL nanocomposites is higher than the neat recycled PP. From the above results the exothermal or endothermal observations confirmed that the recycled PP nanocomposites possess high degree of crystallinity. This can be attributed to the nucleating effect of BAL nanopowder on the crystallization of recycled PP [13]. 


\section{TGA analysis:-}

Thermal stability of the recycled PP and recycled PP/BAL nanocomposites was analyzed using TGA and the results are shown in Fig.4. The thermal degradation parameters, obtained from the TGA thermograms, are also summarized in Table 3. As observed in the thermograms, the weights of the samples decreased with increasing temperature, indicating the thermal destruction of the recycled PP samples. The onset of major thermal degradation temperature of the recycled $\mathrm{PP} / 1 \mathrm{wt} \% \mathrm{BAL}$ nanocomposite $\left(431^{\circ} \mathrm{C}\right)$ was higher than the neat $\mathrm{PP}\left(414^{\circ} \mathrm{C}\right)$, which indicates that the recycled PP nanocomposite is more thermally stable than that of neat recycled PP. This was observed for all the content of BAL nanopowder reinforced recycled PP composites. The increased thermal stability of the recycled PP nanocomposites can be attributed to the higher degree of crystallinity of BAL reinforced recycled PP nanocomposites [14]. Similar behavior was observed as the $T_{\max }$ of all recycled PP nanocomposites are significantly higher than the neat recycled PP, which indicates that the PP/BAL composites are thermally stable at higher temperature.

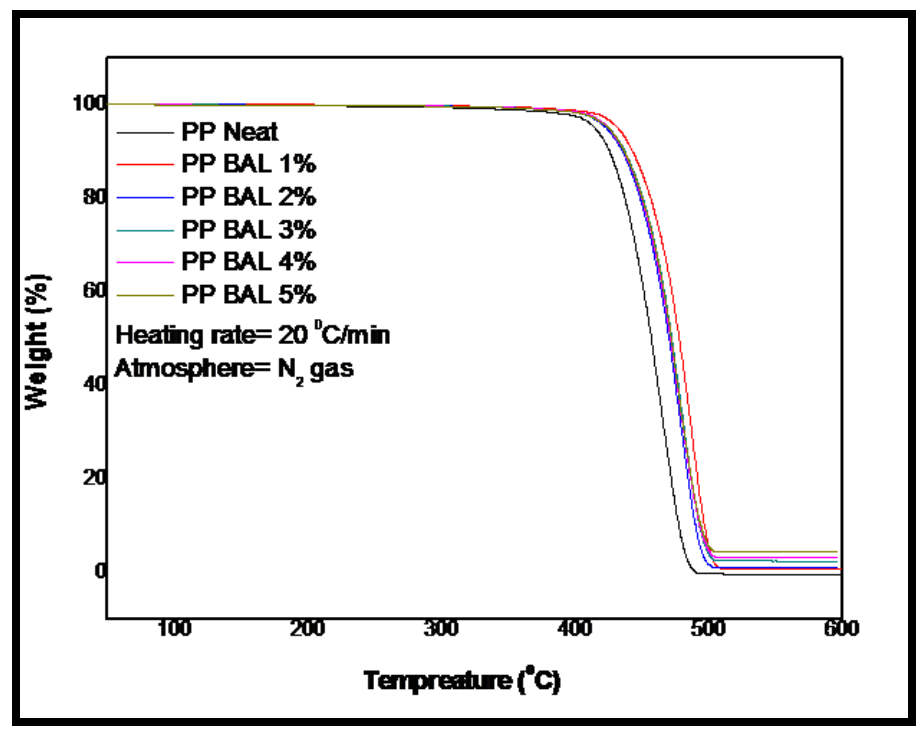

Fig. 4:- TGA analysis of PP/BAL nanocomposites

At the end of the degradation of the recycled PP, it had a $0.25 \%$ char content and the char residue increased with increasing BAL content. The highest amount of charred residue formed (ca. 4\%) is due to the limited transformation to a thermally stable charred material of the reactive species, during decomposition.

Table 3:- Thermogravimeteric analysis of PP/BAL nanocomposites

\begin{tabular}{|l|l|l|l|}
\hline Composites & $\mathbf{T}_{\text {onset, }}\left({ }^{\mathbf{0}} \mathbf{C}\right)$ & $\left.\mathbf{T}_{\max },{ }^{\mathbf{0}} \mathbf{C}\right)$ & Char at $\mathbf{0 . 0} \mathbf{0}^{\mathbf{0}},(\boldsymbol{\%})$ \\
\hline PP & 414 & 456 & 0.25 \\
\hline PP/BAL1\% & 431 & 477 & 0.82 \\
\hline PP/BAL2\% & 422 & 470 & 1.05 \\
\hline PP/BAL3\% & 424 & 471 & 2.5 \\
\hline PP/BAL 4\% & 423 & 471 & 3.25 \\
\hline PP/BAL5\% & 424 & 471 & 4.4 \\
\hline
\end{tabular}

\section{Conclusion:-}

Recycled PP/BAL nanocomposites with different filler contents have been developed. The effect of BAL on the morphology, mechanical and thermal properties of the composites has been studied. The nano filler increased the stiffness of the recycled PP matrix, leading to the enhancement in the mechanical properties of the composites. The results of TGA and DSC experiments indicated that the addition of filler enhanced the thermal stability of the recycled PP nanocomposites. In addition, it was found that BAL significantly affected the crystallization temperature and the degree of crystallization of the recycled PP. The morphology, evaluated using the scanning electron microscopy (SEM), indicated that a uniform dispersion of BAL in the PP matrix was obtained. 


\section{References:-}

1. Hisham A. Maddah. (2016), "Polypropylene as a Promising Plastic: A Review", American Journal of Polymer Science, vol. 6,1-11.

2. G. Guerrica-Echevarria, J. I. Eguiazaibal and J.Nazaibal (1996)," Effects of reprocessing conditionson the properties of unfilledandtalc-filled polypropylene" Polymer Degradation and Stability, vol.53, 1-8.

3. LI, T. Q., C. N. Ng, R, and R. K. Y. LI. (2001), "Impact Behavior of Sawdust/Recycled-PP, Composites", Journal of Applied Polymer Science, vol.81(6), 1420-1428.

4. Srebrenkoska, V.,G. B. Gaceva, M Avella, E. E. Maria, and G. Gennaro. (2009), "Utilization of Recycled Polypropylene for Production of Eco-Composites" Polymer-Plastics Technology and Engineering, Vol. 48(11), $1113-1120$.

5. Dibyaranjan M, and P. Sanjay. (2012). "Secondary Fiber/Recycled Polypropylene Composites" Asian Journal of Research in Chemistry,vol. 5(5), 655-659.

6. Fuad, M. Y. A., H. Hanim, R. Zarina, Z. A. M. Ishak, and A. Hassan.(2010), "Nanofillersimprove themechanical properties ofrecycled polypropylene. Polypropylene/calcium carbonate nanocomposites-effects of processing techniques and maleated polypropylenecompatibiliser", eXPRESS Polymer Letters, vol.4(10), 611-620.

7. Pedrazzoli, D., R. Ceccato, J. Karger-Kocsis, and A. Pegoretti. (2013), "Viscoelastic behaviour and fracture toughness oflinear-low-density polyethylene reinforced with syntheticboehmiten alumina nanoparticles" eXPRESS Polymer Letters, vol. 7(8), 652-666.

8. Santos, P. S., A. C. V. Coelho, H. S. Santos, and P. K. Kiyohara. (2009), "Hydrothermal Synthesis of WellCrystallisedBoehmite Crystals of Various Shapes", Materials Research. 12(4), 437-445.

9. Streller, R. C., R. Thomann, O. Torno, and R. Mülhaupt.(2008), "Isotactic poly(propylene) nanocomposites based upon boehmitenanofillers", Macromolecular Materials and Engineering, vol. 293(3),218-227.

10. Petr, S., K. Trivedi, D. Svobodova, P. Mokrejs, and K. Kolomaznik.(2012), "Effect of Initial Melting Temperature on Crystallization of Polypropylene/OrganoclayNanocomposites" Macromolecular Research, vol. 20(7), 659-666.

11. Modesti,M., A. Lorenzetti, D. Bon, and S. Besco.(2005), "Effect of processing conditions on morphology and mechanical properties of compatibilized polypropylene nanocomposites", Polymer, vol. 46(23), 10237-10245.

12. Patnaik,K.S.K. R., K. S. Devi, and V. K. Kumar.(2010), "Non-isothermal Crystallization Kinetics of Polypropylene (PP) and Polypropylene (PP)/Talc Nanocomposite", InternationalJournal of Chemical Engineering and Applications, vol.1(4), 346-353.

13. Maiti, P., P. H. Nam, and M. Okamoto.(2002), "Influence of Crystallization on Intercalation, Morphology andMechanical Properties of Polypropylene/Clay Nanocomposites", Macromolecules,vol. 35(6), 2042-2049.

14. M. G. Salemane, and A. S. Luyt.(2006), "Thermal and Mechanical Properties ofPolypropylene-Wood Powder Composites", Journal of Applied Polymer Science, vol. 100 (5), 4173-4180. 